\title{
In Vitro Growth of Lens Epithelial Cells from Cataract Patients - Association with Possible Risk Factors for Posterior Capsule Opacification
}

\author{
Karin Sundelin ${ }^{1}$, Anne Petersen ${ }^{1}$, Yalda Soltanpour ${ }^{2}$ and Madeleine Zetterberg ${ }^{*}, 1$ \\ ${ }^{1}$ Institute of Neuroscience and Physiology, Section of Clinical Neuroscience and Rehabilitation/Ophthalmology and \\ ${ }^{2}$ Institute of Biomedicine, Department of Medical Chemistry and Cell Biology, Sahlgrenska Academy at the University of \\ Gothenburg, Sweden
}

\begin{abstract}
Aim: Inter-individual differences in intrinsic proliferative capacity of lens epithelial cells may have importance for the risk of developing posterior capsule opacification (PCO) after cataract surgery. The purpose of the present study was to determine growth of human lens epithelial cells (HLEC) in culture and investigate possible associations with clinical characteristics of the donors, such as age, sex, pseudoexfoliation, uveitis and diabetes.

Methods: Pieces of lens capsule and adhering lens epithelial cells were obtained through capsulorhexis at cataract surgery. Specimens were cultured in a humidified $\mathrm{CO}_{2}$-incubator using standard culture medium and 5\% fetal calf serum for two weeks after which cultured cells were stained with carboxy-fluorescein diacetate succinimidyl ester. Image processing software was used to determine the area of the confluent epithelial cell layer in relation to the size of the original capsule specimen.

Results: The increase in area of confluent HLEC showed a negative correlation with diabetes at the first week after surgery. Lower age and female sex showed border-line significant associations with a higher rate of cell proliferation. The presence of pseudoexfoliation in vivo did not significantly affect cell growth in culture postoperatively. Nor did installation of xylocain in the anterior chamber during surgery.

Conclusion: Diabetes is associated with lower rate of proliferation of lens epithelial cells in culture. The lack of strong correlations between in vitro growth and known risk factors for PCO in the donors suggest that other factors than the proliferative capacity of the cells per se are important for PCO formation.
\end{abstract}

Keywords: Cataract, lens, posterior capsule opacification, primary cell culture, risk factors.

\section{INTRODUCTION}

Contrary to expectations, the incidence of capsulotomy for posterior capsule opacification (PCO) has not declined as predicted $[1,2]$. Various methods to reduce the number of lens epithelial cells, mechanically or pharmacologically, have been investigated $[1,3,4]$. The majority of these preventive methods have not, to date, come into clinical practice. A few studies do indicate that a smaller capsulorhexis size or a close contact between the anterior rhexis and the intraocular lens (IOL) may be beneficial [5-7]. In addition, two studies demonstrate lower PCO scores after treatment with immunotoxin MDX-A [8, 9]. However, most successful PCO prevention has been achieved thanks to appropriate design of the IOL, i.e. a sharp IOL optic edge [10]. Although the use of sharp-edged IOLs initially appeared to reduce the prevalence of PCO, recent reports have shown that the need for neodymium:YAG (Nd:YAG) laser capsulotomy is not as low as expected, but instead postponed, and other means than the IOL design have to be

*Address correspondence to this author at the Institute of Neuroscience and Physiology, Department of Clinical Neuroscience and Rehabilitation/ Ophthalmology, the Sahlgrenska Academy at the University of Gothenburg, Sahlgrenska University Hospital, SE-431 80 Mölndal, Sweden; Tel: +46-3178633 94; Fax: +46-31-41 29 04; E-mail: madeleine.zetterberg@gu.se considered to prevent PCO [11-13]. Extended knowledge about patient-associated risk factors could lead to ways of developing new preventive strategies.

Suggested risk factors for PCO are age [14-17], female sex $[16,18,19]$, pseudoexfoliation $[20,21]$, diabetes mellitus [22-25], uveitis [26-29], retinitis pigmentosa [18] and myopia $[30,31]$. The present study was designed to study human lens epithelial cells (HLEC) from cataract patients in culture and investigate if cell growth was associated with suggested risk factors for PCO.

\section{METHODS}

Human lens capsule epithelium specimens, i.e. the $5 \mathrm{~mm}$ in diameter central part of the anterior lens capsule together with the adhering single layer of cuboidal epithelial cells, were obtained from lenses during cataract surgery at the Eye Clinic, Sahlgrenska University Hospital, Mölndal after informed consent from the patients. The study was approved by The Regional Ethics Committee in Gothenburg, Västra Götaland County, Sweden, and the tenets of the Declaration of Helsinki were followed. The human lens epithelium specimens, approximately $5 \mathrm{~mm}$ in diameter, were placed in Eppendorf tubes containing standard culture medium (RPMI-1640) supplemented with $10 \%$ fetal calf serum (FCS), $100 \mathrm{U} \mathrm{ml}^{-1}$ penicillin, $0.1 \mathrm{mg} \mathrm{ml}^{-1}$ streptomycin and 
$2 \mathrm{mM}$ L-glutamine immediately after surgery. The lens epithelium specimens were stored in room temperature for up to 24 hours, after which they were transferred from the Eppendorf tubes to 24-well culture dishes (TPP, Switzerland) containing new cell culture medium, same as above but freshly prepared with 5\% FCS. We have previously seen that a concentration of FCS of $10 \%$ is beneficial when collecting the samples, whereas 5\% FCS is enough when culturing the specimens. The capsules were allowed to settle freely at the bottom of the culture well, without any measures to ensure that they would be positioned face up or down, since previous work in our laboratory has shown that this type of manipulation causes extensive damage to the specimens. Also, even if the position of the capsules, face up or down, should have any effect on cell growth this would affect specimens derived from all groups and hence not influence the outcome of the study. The culture dishes were subsequently put into a humidified $\mathrm{CO}_{2}$-incubator at $37{ }^{\circ} \mathrm{C}$ to allow the capsules to attach to the bottom of the culture wells.

After one week, cultured cells were incubated with carboxy-fluorescein diacetate succinimidyl ester (CFDA SE) for 15 minutes at room temperature. CFDA SE (Vybrant CFDA SE, Invitrogen, Eugene, OR, USA) is a fluorogenic compound that, upon entering metabolically active cells, makes them fluorescent (excitation $492 \mathrm{~nm}$, emission 517 $\mathrm{nm}$ ). Being non-toxic to the cells, CFDA SE does not affect further growth of the cells, enabling continuous monitoring of proliferation. One week after the first staining procedure, however, the fluorescence had faded and cells were again incubated with CFDA SE. Prior to staining, a stock solution of $10 \mathrm{mM}$ CFDA SE was prepared in dimethyl sulfoxide (DMSO). This stock solution was then further diluted to $10 \mu \mathrm{M}$ in preheated phosphate buffered saline (PBS). After 15 minutes the CFDA SE solution was replaced by freshly prepared cell culture medium with 5\% FCS and lens capsule epithelium specimens were viewed and photographed in a confocal microscope (Nikon Eclipse TE300 C1) using a

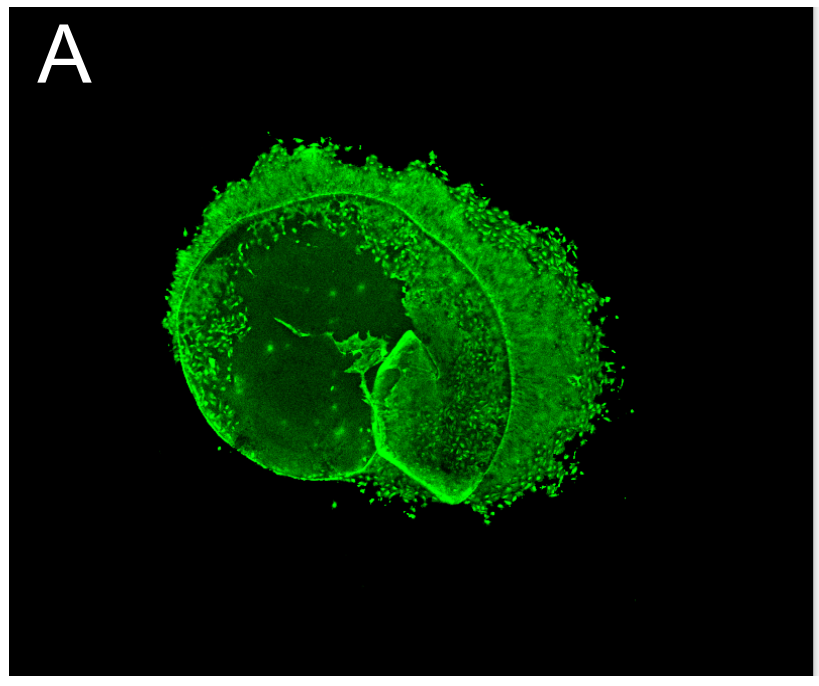

Nikon D-Eclipse C1 camera and EZ-C1 3.30 Gold as imaging software. Fig. (1) shows an example of a capsulorhexis specimen after staining with CFDA SE after 1 and 2 weeks of culture respectively.

The area of the fluorescent lens capsule epithelium specimens was determined after one and two weeks of culture using image processing software (ImageJ, National Institutes of Health, USA). The total area of the confluent lens epithelium layer, including the lens capsule, was related to the area of the capsule alone. The increase in cell layer surface was then compared with several clinical characteristics of the cataract patients. Since the increase in cell growth was not normally distributed, non-parametric methods were used to test for statistically significant associations, including Spearman's rho correlation test and Mann-Whitney U-test. After Bonferroni correction for multiple comparisons (three different time points), significance was set at $P<0.017$. SPSS 16.0 (SPSS Inc, Chicago, Il) was used as statistic software.

\section{RESULTS}

Lens capsule epithelium specimens from 270 cataract patients were monitored and the increase in area of confluent cells was determined after one and two weeks respectively. Fig. (1) shows an example of a capsulorhexis specimen after staining with CFDA SE after 1 and 2 weeks of culture respectively. Demographic and clinical characteristics of these 270 cataract patients are given in Table 1. Mean age was 73.5 years (range 32-97) and $63.3 \%$ were women. Pseudoexfoliation was common $(24.8 \%$,) whereas only 6 patients $(2.3 \%)$ had a history of uveitis. 32 patients $(12.4 \%)$ had diabetes mellitus, including both insulin-dependent and non-insulin-dependent diabetes. In $44.4 \%$ of the cataract patients, lidocaine $10 \mathrm{mg} / \mathrm{ml}$ was instilled in the anterior chamber during surgery and in 7 cases $(2.8 \%)$, trypan blue ophthalmic solution $(0.06 \%$ Vision Blue or $0.055 \%$ Mono Blue) was used to stain the lens capsule during surgery.

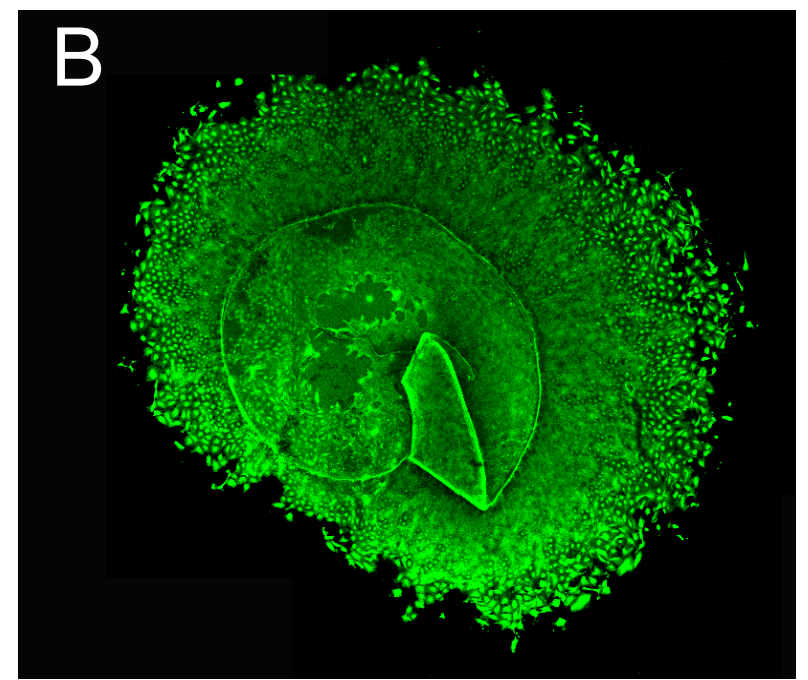

Fig. (1). Human lens capsule epithelium specimens after 1 and 2 weeks of culturing respectively. Human lens capsule epithelium specimens were obtained at cataract surgery. Figs. (1A, B) show the same specimen, derived from an 85-year-old woman, after 1 week (A) and 2 weeks (B) respectively. The size of the capsule before outgrowth of epithelial cells was $5 \mathrm{~mm}$. Lens epithelium cells were stained with the non-toxic fluorogenic compound carboxy-fluorescein diacetate succinimidyl ester (CFDA SE) to facilitate monitoring of cell growth. Original magnification $\mathrm{x} 20$ is shown. 
Table 1. Demographic data on cataract patients.

\begin{tabular}{|c|c|}
\hline Characteristic & Number of Patients $(\%)^{\dagger}$ \\
\hline Age (years), mean $\pm \mathrm{SD}$ & $73.5 \pm 11.2$ \\
\hline \multicolumn{2}{|l|}{ Sex } \\
\hline Female & $171(63.3)$ \\
\hline Male & 99 (36.7) \\
\hline \multicolumn{2}{|c|}{ Pseudoexfoliation present $(\mathrm{N}=\mathbf{2 5 8})$} \\
\hline Yes & $64(24.8)$ \\
\hline No & $194(75.2)$ \\
\hline \multicolumn{2}{|c|}{ History of uveitis $(\mathrm{N}=\mathbf{2 5 9})$} \\
\hline Yes & $6(2.3)$ \\
\hline No & $253(97.7)$ \\
\hline \multicolumn{2}{|l|}{ Diabetes $^{\ddagger}(\mathrm{N}=259)$} \\
\hline Yes & $32(12.4)$ \\
\hline No & $227(87.6)$ \\
\hline \multicolumn{2}{|l|}{ Xylocain in AC ( $N=259)$} \\
\hline Yes & $115(44.4)$ \\
\hline No & $144(55.6)$ \\
\hline \multicolumn{2}{|c|}{ Trypan blue in AC ( $\mathrm{N}=252)$} \\
\hline Yes & $7(2.8)$ \\
\hline No & $245(97.2)$ \\
\hline
\end{tabular}

Cell growth is presented in Table 2. There was a borderline significant inverse correlation between the increase in the area of confluent lens epithelial cells and the age of the cataract patient after the second week of culture $(\mathrm{p}=0.035$, Spearman's rho correlation test). The same negative trend was seen when examining the whole culture period (the first two weeks). Female sex showed a trend of higher rate of cell growth at all studied time points, but this difference was not significant after correction for multiple comparisons $(\mathrm{p}=0.037$, Mann-Whitney U-test for the whole culture period). Lens epithelial cells from diabetic cataract patients exhibited a lower rate of proliferation after the first week of culture ( $\mathrm{p}=0.005$, Mann-Whitney U-test).

\section{DISCUSSION}

The demographics of the study population (i.e. age and sex) appears to be representative of Swedish cataract patients in general. Mean age (73.5 years) and the proportion of women $(63.3 \%)$ seen in this study are close to the mean age (76.1 years) and sex distribution (66\% women) reported from the Swedish National Cataract Register [32].

Young age is uncontroversial as a risk factor for PCO as shown by several authors [14-17]. This seems to be the case regarding cell growth in the present study as well, although the number of very young patients was small. The lowest quartile of the study population included cataract patients between 32 and 67 years old.

Table 2. Increase in area of confluent lens epithelial cells in relation to clinical parameters.

\begin{tabular}{|c|c|c|c|}
\hline \multirow{2}{*}{ Parameter } & \multicolumn{3}{|c|}{ Cell Growth (\% Increased Area of Confluent HLEC) ${ }^{\dagger}$} \\
\hline & 1st week & 2nd Week & Total Period \\
\hline Age & $\mathrm{R}=0.019$ & $\mathrm{R}=-0.137^{\star}$ & $\mathrm{R}=-0.073$ \\
\hline \multicolumn{4}{|l|}{ Sex } \\
\hline Female & $69(11-141)$ & $80(46-114)$ & $231(159-327)$ \\
\hline Male & $55(20-110)$ & $76(52-113)$ & $201(140-276)^{\S}$ \\
\hline \multicolumn{4}{|c|}{ Pseudoexfoliation present } \\
\hline Yes & $56(11-149)$ & $69(45-110)$ & $203(117-324)$ \\
\hline No & $64(19-128)$ & $80(50-114)$ & $218(154-320)$ \\
\hline \multicolumn{4}{|c|}{ History of uveitis } \\
\hline Yes & $89(24-159)$ & $126(70-134)$ & $238(174-328)$ \\
\hline No & $64(14-133)$ & $79(49-113)$ & $215(142-321)$ \\
\hline \multicolumn{4}{|l|}{ Diabetes } \\
\hline Yes & $29(3-82)^{\pi}$ & $90(60-127)$ & $180(109-264)$ \\
\hline No & $69(19-139)$ & $78(49-114)$ & $219(154-322)$ \\
\hline \multicolumn{4}{|c|}{ Xylocain in AC } \\
\hline Yes & $62(14-131)$ & $86(50-118)$ & $217(157-332)$ \\
\hline No & $64(15-134)$ & $75(46-110)$ & $211(139-313)$ \\
\hline \multicolumn{4}{|c|}{ Trypan blue in AC } \\
\hline Yes & $60(1-69)$ & $72(25-97)$ & $158(27-232)$ \\
\hline No & $64(17-134)$ & $80(50-116)$ & $217(151-322)$ \\
\hline
\end{tabular}

Cell growth was calculated as the increase in area of confluent HLEC the $1^{\text {st }}$ week (day 1-7) and the $2^{\text {nd }}$ week (day 8-14) respectively, as related to the area of the lens capsule. In addition, the increase in area of confluent HLEC after two weeks of cell culture was determined in relation to the lens capsule (total period, day 1-14). Data are presented as median with $25^{\text {th }}$ and $75^{\text {th }}$ percentiles, unless otherwise stated. HLEC=human lens epithelial cells. $\mathrm{R}=$ correlation coefficient. After Bonferroni correction for multiple comparisons (three different time points), significance was set at $P<0.017$. ${ }^{\ddagger} \mathrm{p}=0.035$, Spearman's rho correlation test. ${ }^{\S} \mathrm{p}=0.037$, Mann-Whitney U-test. " $\mathrm{p}=0.005$, Mann-Whitney U-test. $\mathrm{AC}=$ anterior chamber.

Female sex showed a trend of higher rate of cell proliferation in this study, although the association was not significant after compensating for multiple comparisons. This may be attributable to the limited number of patients, since the power of the study with regard to sex was only $42 \%$, based on a standardized difference of 0.2 (as calculated from the study of Ninn-Pedersen and Bauer, 1997) or from the association being weak. There are several studies indicating female sex as a risk for PCO development [16, 18, 19], and they are supported by the present findings. However, others have not shown this sex difference $[12,17$, 20], indicating that the impact of sex, if any, is relatively small. Although the mitogenic effect of estrogens on binding to their receptors is well known, it is now also well established that estrogens can exert pro-apoptotic effects. In the anterior pituary gland, estrogens are responsible for inducing both proliferation and cell death during the estrous cycle by sensitizing the cells to pro-apoptotic as well as 
mitotic stimuli such as dopamine, TNF-alpha and FasL [33]. Estrogen receptors have been demonstrated in human lens epithelium [34], but sex-specific differences in estrogen receptor expression or sensitivity for exogenous estrogen in lens cells have not yet been studied. The current study does indicate that there may be sex-specific differences in proliferative rate of HLEC even without the presence of exogenous estrogen.

The prevalence of pseudoexfoliation (PEX) is high in Scandinavian countries, ranging between 11 and $40 \%$ in age groups comparable to the age group in this study [35-37]. Of the 270 cataract patients in the present study, $24.8 \%$ exhibited PEX. Previous studies have shown that PCO is more common in patients with PEX [20]. However, in this study, lens epithelial cells from patients with PEX did not differ in cell growth as compared with cells from patients without PEX. Based on the study by Küchle et al. (1997), a standardized difference of 0.44 , yielding a power of $95 \%$ was obtained, indicating that this lack of association was not spurious.

Lens epithelial cells from cataract patients with diabetes exhibited a lower rate of proliferation after the first week of culture. The power of the study, $99 \%$ with regard to diabetes as a risk/protective factor for PCO, as derived from a standardized difference of 0.65 [20], suggests that this association is correct. However, the difference in cell growth between diabetics and non-diabetics was no longer evident after the second week, indicating that if diabetes does indeed affect cell proliferation, it probably does not play a major role, or at least is not an intrinsic property of HLEC from diabetic patients.

Patients with a history of uveitis or for whom trypan blue had been used during surgery were too few to draw any conclusions regarding these two groups. Portes et al. (2010) have published results of increased lens cell death from trypan blue $0.1 \%$ [38]. Lidocain $1 \%$ has been suggested to be protective against PCO in vitro in a rabbit model [39]. This was not confirmed in the present study.

It has been suggested that cataract type also might play a role in PCO development [40, 41], with a smaller number of viable HLECs in mature cataracts. Information about cataract type was not included in the present study. However, we used relative growth and not absolute growth of cells as our main outcome, thus attempting to compensate for differing cell densities from the start of the cell culture.

The part of the lens capsule obtained for culture in this work was derived from the central anterior lens capsule through capsulorhexis. Most mitoses are normally seen in the germinative zone adjacent to the equatorial zone in the lens. That part of the lens capsule was not readily available for culture. However, although the central part of the lens epithelium exhibits very low mitotic activity, experiments using labeling with tritiated thymidine $\left({ }^{3} \mathrm{H}-\mathrm{Tdr}\right)$ have identified those centrally located lens epithelium cells as stem cells [42]. Characteristic features of stem cells are their unlimited proliferative capacity, although they have a low proliferative rate at normal conditions. In cases of tissue damage, stem cells can be recruited and rapidly induce a high mitotic activity [43]. Hence, the central part of the lens epithelium derived through capsulorhexis may even better reflect the proliferative potential of HLEC than the germinative zone. In addition to proliferation of cells, migration may also have affected the results, since total area covered by HLEC was measured. This is well in line with techniques used to quantify PCO in clinical studies, such as Evaluation of Posterior Capsule Opacification (EPCO).

PCO is usually described in terms of two different morphologic types; regeneratory and fibrotic PCO. The former is thought to originate from the peripheral/equatorial epithelium and is characterized by proliferation/migration of HLEC as well as differentation in the form of Elschnig pearls, which is considered an attempt to form new lens fibres. The latter is believed to be derived from the central/anterior lens epithelium and has been linked to epithelial-mesenchymal transition, leading to fibrosis and contraction of the capsular bag. In this study, a typical epithelial morphology was retained throughout the culture period, without formation of lentoids/Elschnig pearls or any signs of capsule wrinkling. This is probably due to the short time of culture, which did not enable the cells to differentiate. The short duration of cell culture was an elaborate choice since a short interval between surgery and cell growth evaluation would better reflect the characteristics of the donors. Since it could not be excluded that the extent of surgical trauma would influence cell proliferation, we decided to investigate the first and second week separately.

In conclusion, the only significant association between in vitro growth of lens epithelial cells and donor characteristics shown in this study was diabetes mellitus, the mechanism of which remains to be elucidated. The present study suggests that characteristics of individual patients, at least with regard to lens epithelial cells cultured in vitro, may be less important than other factors such as surgical technique or IOL design, in determining the risk of PCO.

\section{CONFLICT OF INTEREST}

No author has a financial or proprietary interest in any material or method mentioned.

\section{ACKNOWLEDGEMENTS}

Supported by the Swedish Research Council (\#20113132), Swedish government ("Agreement concerning research and education of doctors"; ALF-GBG-145921), Göteborg Medical Society, Marianne and Marcus Wallenberg Foundation, Hjalmar Svensson Foundation, Herman Svensson Foundation, Greta Andersson Foundation, Ögonfonden and Kronprinsessan Margaretas Arbetsnämnd för Synskadade.

\section{REFERENCES}

[1] Awasthi N, Guo S, Wagner BJ. Posterior capsular opacification: a problem reduced but not yet eradicated. Arch Ophthalmol 2009; 127: 555-62.

[2] Apple DJ, Peng Q, Visessook N, et al. Eradication of posterior capsule opacification: documentation of a marked decrease in $\mathrm{Nd}$ :YAG laser posterior capsulotomy rates noted in an analysis of 5416 pseudophakic human eyes obtained postmortem. Ophthalmology 2001; 108: 505-18.

[3] Walker TD. Pharmacological attempts to reduce posterior capsule opacification after cataract surgery--a review. Clin Experiment Ophthalmol 2008; 36: 883-90.

[4] Wormstone IM, Wang L, Liu CS. Posterior capsule opacification. Exp Eye Res 2009; 88: 257-69. 
[5] Aykan U, Bilge AH, Karadayi K, Akin T. The effect of capsulorhexis size on development of posterior capsule opacification: small $(4.5$ to $5.0 \mathrm{~mm})$ versus large $(6.0$ to $7.0 \mathrm{~mm})$. Eur J Ophthalmol 2003; 13: 541-5.

[6] Wejde G, Kugelberg M, Zetterström C. Position of anterior capsulorhexis and posterior capsule opacification. Acta Ophthalmol Scand 2004; 82: 531-4.

[7] Hollick EJ, Spalton DJ, Ursell PG, et al. The effect of polymethylmethacrylate, silicone, and polyacrylic intraocular lenses on posterior capsular opacification 3 years after cataract surgery. Ophthalmology 1999; 106: 49-55.

[8] Clark DS, Emery JM, Munsell MF. Inhibition of posterior capsule opacification with an immunotoxin specific for lens epithelial cells: 24 month clinical results. J Cataract Refract Surg 1998; 24: 161420.

[9] Meacock WR, Spalton DJ, Hollick EJ, Boyce JF, Barman S, Sanguinetti G. Double-masked prospective ocular safety study of a lens epithelial cell antibody to prevent posterior capsule opacification. J Cataract Refract Surg 2000; 26: 716-21.

[10] Findl O, Buehl W, Bauer P, Sycha T. Interventions for preventing posterior capsule opacification. Cochrane Database Syst Rev 2007; (3): CD003738.

[11] Cleary G, Spalton DJ, Koch DD. Effect of square-edged intraocular lenses on neodymium:YAG laser capsulotomy rates in the United States. J Cataract Refract Surg 2007; 33: 1899-906.

[12] Johansson B. Clinical consequences of acrylic intraocular lens material and design: Nd:YAG-laser capsulotomy rates in $3 \times 300$ eyes 5 years after phacoemulsification. Br J Ophthalmol 2010; 94 : 450-55.

[13] Vock L, Menapace R, Stifter E, Findl O, Georgopoulos M. Clinical effects of primary posterior continuous curvilinear capsulorhexis in eyes with single-piece hydrophilic acrylic intraocular lenses with and without haptic angulation. J Cataract Refract Surg 2007; 33: 258-64.

[14] Hosal BM, Biglan AW. Risk factors for secondary membrane formation after removal of pediatric cataract. J Cataract Refract Surg 2002; 28: 302-9.

[15] Dholakia SA, Vasavada AR, Singh R. Prospective evaluation of phacoemulsification in adults younger than 50 years. J Cataract Refract Surg 2005; 31: 1327-33.

[16] Ninn-Pedersen K, Bauer B. Cataract patients in a defined Swedish population 1986-1990. VI. YAG laser capsulotomies in relation to preoperative and surgical conditions. Acta Ophthalmol Scand 1997; 75: 551-7.

[17] Prajna NV, Ellwein LB, Selvaraj S, Manjula K, Kupfer C. The madurai intraocular lens study IV: posterior capsule opacification. Am J Ophthalmol 2000; 130: 304-9.

[18] Ando H, Ando N, Oshika T. Cumulative probability of neodymium: YAG laser posterior capsulotomy after phacoemulsification. J Cataract Refract Surg 2003; 29: 2148-54.

[19] Auffarth GU, Brezin A, Caporossi A, et al. Comparison of Nd:YAG capsulotomy rates following phacoemulsification with implantation of PMMA, silicone, or acrylic intra-ocular lenses in four European countries. Ophthalmic Epidemiol 2004; 11: 319-29.

[20] Kuchle M, Amberg A, Martus P, Nguyen NX, Naumann GO. Pseudoexfoliation syndrome and secondary cataract. $\mathrm{Br} \mathrm{J}$ Ophthalmol 1997; 81: 862-6.

[21] Abela-Formanek C, Amon M, Schauersberger J, et al. Uveal and capsular biocompatibility of 2 foldable acrylic intraocular lenses in patients with uveitis or pseudoexfoliation syndrome: comparison to a control group. J Cataract Refract Surg 2002; 28: 1160-72.

[22] Hayashi H, Hayashi K, Nakao F, Hayashi F. Elapsed time for capsular apposition to intraocular lens after cataract surgery. Ophthalmology 2002; 109: 1427-31.
[23] Ebihara Y, Kato S, Oshika T, Yoshizaki M, Sugita G. Posterior capsule opacification after cataract surgery in patients with diabetes mellitus. J Cataract Refract Surg 2006; 32: 1184-7.

[24] Ionides A, Dowler JG, Hykin PG, Rosen PH, Hamilton AM. Posterior capsule opacification following diabetic extracapsular cataract extraction. Eye 1994; 8: 535-7.

[25] Zaczek A, Zetterstrom C. Posterior capsule opacification after phacoemulsification in patients with diabetes mellitus. J Cataract Refract Surg 1999; 25: 233-7.

[26] Suresh PS, Jones NP. Phacoemulsification with intraocular lens implantation in patients with uveitis. Eye 2001; 15: 621-8.

[27] Rauz S, Stavrou P, Murray PI. Evaluation of foldable intraocular lenses in patients with uveitis. Ophthalmology 2000; 107: 909-19.

[28] Krishna R, Meisler DM, Lowder CY, Estafanous M, Foster RE. Long-term follow-up of extracapsular cataract extraction and posterior chamber intraocular lens implantation in patients with uveitis. Ophthalmology 1998; 105: 1765-9.

[29] Dana MR, Chatzistefanou K, Schaumberg DA, Foster CS. Posterior capsule opacification after cataract surgery in patients with uveitis. Ophthalmology 1997; 104: 1387-94.

[30] Hayashi K, Yoshida M, Hayashi H. Posterior capsule opacification in myopic eyes. J Cataract Refract Surg 2006; 32: 634-8.

[31] Vasavada AR, Shah A, Raj SM, Praveen MR, Shah GD. Prospective evaluation of posterior capsule opacification in myopic eyes 4 years after implantation of a single-piece acrylic IOL. J Cataract Refract Surg 2009; 35: 1532-9.

[32] Lundström M, Stenevi U, Thorburn W. The Swedish National Cataract Register: a 9-year review. Acta Ophthalmol Scand 2002; 80: 248-57.

[33] Zarate S, Zaldivar V, Jaita G, et al. Role of estrogens in anterior pituitary gland remodeling during the estrous cycle. Front Horm Res 2010; 38: 25-31.

[34] Cammarata PR, Flynn J, Gottipati S, et al. Differential expression and comparative subcellular localization of estrogen receptor beta isoforms in virally transformed and normal cultured human lens epithelial cells. Exp Eye Res 2005; 81: 165-75.

[35] Arnarsson AM. Epidemiology of exfoliation syndrome in the Reykjavik Eye Study. Acta Ophthalmol Scand 2009; 87 Thesis 3: $1-17$.

[36] Ekström C, Alm A. Pseudoexfoliation as a risk factor for prevalent open-angle glaucoma. Acta Ophthalmol Scand 2008; 86: 741-6.

[37] Mönestam EI. Incidence of dislocation of intraocular lenses and pseudophakodonesis 10 years after cataract surgery. Ophthalmology 2009; 116: 2315-20.

[38] Portes AL, Almeida AC, Allodi S, Monteiro ML, Miguel NC. Trypan blue staining for capsulorhexis: ultrastructural effect on lens epithelial cells and capsules. J Cataract Refract Surg 2010; 36: 582-7.

[39] Vargas LG, Escobar-Gomez M, Apple DJ, Hoddinott DS, Schmidbauer JM. Pharmacologic prevention of posterior capsule opacification: in vitro effects of preservative-free lidocaine $1 \%$ on lens epithelial cells. J Cataract Refract Surg 2003; 29: 1585-92.

[40] Argento C, Nunez E, Wainsztein R. Incidence of postoperative posterior capsular opacification with types of senile cataracts. J Cataract Refract Surg 1992; 18: 586-8.

[41] Argento C, Zarate J. Study of the lens epithelial cell density in cataractous eyes operated on with extracapsular and intercapsular techniques. J Cataract Refract Surg 1990; 16: 207-10.

[42] Zhou M, Leiberman J, Xu J, Lavker RM. A hierarchy of proliferative cells exists in mouse lens epithelium: implications for lens maintenance. Invest Ophthalmol Vis Sci 2006; 47: 2997-3003.

[43] Lavker RM, Sun TT. Epidermal stem cells: properties, markers, and location. Proc Natl Acad Sci USA 2000; 97: 13473-5. 